Cita bibliográfica: Henrique da Silva Maranhão, C. y Fransualdo de Azevedo, F. (2019). O uso da teoria do espaço geográfico de Milton Santos no estudo do turismo: uma possibilidade metodológica em nível dos programas de pós-graduação stricto sensu em Geografia no Brasil. Investigaciones Turísticas (18), pp. 95-118. http://dx.doi. org/10.14198/INTURI2019.18.05

\title{
O uso da teoria do espaço geográfico de Milton Santos no estudo do turismo: uma possibilidade metodológica em nível dos programas de pós-graduação stricto sensu em Geografia no Brasil
}

The use of Milton Santos' theory of geographic space in the study of tourism: a methodological possibility at the level of the stricto sensu postgraduate programs in Geography in Brazil

El uso de la teoría del espacio geográfico de Milton Santos en el estudio del turismo: una posibilidad metodológica a nivel de los programas de postgrado stricto sensu en Geografía en Brasil

Christiano Henrique da Silva Maranhão, Universidade Federal do Rio Grande do Norte- UFRN, Brasil christianomaranhao@gmail.com

Francisco Fransualdo de Azevedo, Universidade Federal do Rio Grande do Norte- UFRN, Brasil ffazevedo@gmail.com

\section{RESUMO}

A contemporaneidade testemunha o turismo despontando como temática de estudo para distintas ciências, encontrando na Geografia uma dessas possibilidades. Sabendo disto, busca-se identificar a relevância da teoria do espaço geográfico, de autoria do geógrafo Milton Santos, no que se refere ao fornecimento de subsídios metodológicos para a estruturação de estudos (teses e dissertações) que abordam o turismo como tema de pesquisa, no âmbito dos programas de pós-graduação stricto sensu em Geografia no Brasil. Metodologicamente trata-se de uma pesquisa exploratório-descritiva, de viés qualitativo. Utiliza-se da análise temática e do levantamento bibliográfico como ferramentas metodológicas centrais. Relata-se que 35 pesquisas, de 49 analisadas, fizeram uso de elementos e categorias de análise propostos por Milton Santos, e 19\% destes estudos estão amparados diretamente pela teoria do espaço geográfico. Destarte, conclui-se que a aludida teoria apresenta relevância no momento dos pesquisadores elencarem os suportes técnicos e metodológicos para estruturação dos estudos geográficos sobre o turismo no Brasil. 
Palavras-chave: teoria do espaço geográfico; possibilidade metodológica; estudos do turismo; pós-graduação em geografia; Brasil.

\section{ABSTRACT}

In recent times tourism has been emerging as a theme of study for different sciences, including Geography. In this respect, the aim of this paper is to identify the relevance of the geographic space theory, authored by geographer Milton Santos, regarding the provision of theoretical-methodological subsidies for the structuring of studies (theses and dissertations) that approach tourism as a research theme, in the scope of the stricto sensu postgraduate programs in Geography in Brazil. Methodologically speaking, this is an exploratory-descriptive study that takes a qualitative approach. Thematic analysis and a bibliographic survey are used as the main methodological tools. Of the 49 studies analysed, it has been found that 35 made use of elements and categories of analysis proposed by Milton Santos, and 19\% of these studies are supported directly by the geographic space theory. Thus, it may be concluded that the aforementioned theory is relevant for structuring the geographic studies on tourism in Brazil.

Keywords: geographic space theory; methodological possibility; tourism studies; postgraduate studies in geography; Brazil.

\section{RESUMEN}

La contemporaneidad testimonia el turismo disponiendo como temática de estudio para distintas ciencias, encontrando en la Geografía una de esas posibilidades. En este sentido, se busca identificar la relevancia de la teoría del espacio geográfico, de autoría del geógrafo Milton Santos, en lo que se refiere al suministro de bases teóricas y metodológicas para la estructuración de estudios (tesis y disertaciones) que abordan el turismo como tema de investigación, en el marco de los programas de postgrado stricto sensu en Geografía en Brasil. Metodológicamente se trata de una investigación exploratoria-descriptiva, de sesgo cualitativo. Se utiliza el análisis temático y la revisión bibliográfica como herramientas metodológicas centrales. 35 encuestas de 49 analizadas, hicieron uso de elementos y categorías de análisis propuestos por Milton Santos, y el 19\% de estos estudios están amparados directamente por la teoría del espacio geográfico. De ahí, se concluye que esta teoría tiene relevancia para la estructuración de los estudios geográficos sobre turismo en Brasil.

Palabras clave: teoría del espacio geográfico; posibilidad metodológica; estudios del turismo; postgrado en geografía; Brasil.

\section{INTRODUÇÃO}

A contemporaneidade testemunha o avanço significativo do turismo enquanto campo de estudo científico. É possível destacar o esforço de turismólogos em progredir no saber agregado à respectiva área, como também é permitido pontuar o interesse de pesquisadores de ciências contíguas em estudar o turismo, em decorrência dos impactos que ele produz em seus diferentes objetos de pesquisa. 
Como resultado deste cenário nota-se a ampliação do escopo dos estudos sobre o turismo, que se ramifica em questões que abordam a práxis do fenômeno a partir de diferentes perspectivas: industrial, comercial, política, comunitária, ambiental dentre outras. Destarte, pontua-se que o estudo do turismo é complexo e utiliza de conceitos, teorias e elementos de significados polissêmicos, e oriundos de distintas áreas do conhecimento (Castrogiovanni, 2004; Silva, 2012).

Assim, destaca-se que o turismo encontra na Geografia uma possibilidade efetiva de construção de suas bases epistemológicas (Albach e Gândara, 2011). Sabendo que o interesse recíproco procede, uma vez que a Geografia por ser uma ciência de representatividade plural (Pearce, 2003) também vem se empenhando pelo estudo do turismo a partir de diversas denominações: Geografia do turismo, Geografia turística e Geografia da recreação (Rejowski, 1996).

Ao meditar sobre a relação acadêmico-científica estabelecida entre o turismo e a Geografia é possível atestar seu caráter histórico a partir de fatos que marcam essa afinidade. Sabe-se que o primeiro registro de interesse epistemológico de um geógrafo pelo turismo ocorre em 1841, quando o austríaco Kohl (século XIX) inicia seus estudos motivado pela transformação do meio natural, promovida pelo deslocamento turístico (Gómez, 1987).

De forma associada, destaca-se o ano de 1905 como o período em que outro geógrafo austríaco, chamado de Joseph Stradner, denominou de Geografia do turismo, Fremdenverkehrsgeographie, todo conhecimento produzido sobre o fenômeno turístico a partir da abordagem geográfica. Enfatiza-se que os estudos deste tempo centralizavam-se nos efeitos positivos do turismo na balança de pagamentos (Castro, 2006).

Expõe-se ainda que em 1919, um geógrafo alemão chamado Sputz, em sua tese de doutorado de título Die Geographischen Bedigungen und Wirkungen dês Fremdenverkehrs in tirol ${ }^{1}$, se dedicou a pesquisar a relação estabelecida entre o turismo e o deslocamento espacial (Gómez, 1987).

No cenário brasileiro é possível citar a tese do professor Dr. Armando Corrêa da Silva, O litoral norte do estado de São Paulo: formação da região periférica, defendida em 1975 no Departamento de Geografia da Faculdade de Filosofia, Letras e Ciências Humanas da Universidade de São Paulo (USP), como o primeiro esforço acadêmico-científico da Geografia brasileira em função da temática do turismo. Informa-se que a aludida tese fez uma leitura simplista do turismo no estado de São Paulo, reflexo direto de uma atividade que ainda era carente de estrutura de mercado e organização estatal (Castro, 2006; Silva, 1975).

Entretanto, quando se busca pelo primeiro trabalho geográfico em nível de pós-graduação stricto sensu no Brasil, que se dedicou ao estudou do turismo como temática central de pesquisa, é permitido destacar a tese de Kleber M. B. Assis intitulada de: $O$ turismo interno no Brasil, datada de 1976 e defendida no Departamento de Geografia da Universidade Federal do Rio Grande do Sul (Rodrigues, 2001). O aludido estudo apresentou um perfil descritivo, sendo

1. Tradução livre: Condicionantes geográficos e efeitos do turismo no tirol. 
composto por um expressivo volume de dados que, como de praxe, apontam para os aspectos econômicos do turismo.

Por todo o exposto, é permito dizer que a abordagem geográfica do turismo se estabelece por meio do estudo relacional entre os deslocamentos (cerne da prática do turismo) e os suportes oferecidos pelas materialidades (infraestruturas públicas e turísticas), reconhecendo esta sinergia como a possibilidade central da circulação de fluxos (pessoas, mercadorias e capital) através do espaço, elemento determinante para que a experiência turística aconteça. Cruz (2001) afirma que o turismo é uma prática social que consome elementarmente o espaço.

Relata-se que o conceito de espaço, estudado pela Geografia, recebe o adjetivo de geográfico, e é compreendido "como um conjunto de relações realizadas através de funções e formas que se apresentam como testemunho de uma história escrita por processos do passado e do presente" (Santos, 1996, p.122). Observa-se que estes processos mencionados pelo autor dotam o espaço de novas funcionalidades e usos (inclusive o uso turístico), e acabam norteando o entendimento do turismo como um fenômeno socioespacial que faz uso, interfere, transforma, produz e consome o espaço geográfico.

Na base dessas relações, destaca-se o esforço intelectual e científico do geógrafo Milton Santos sobre a temática do espaço, uma vez que o referido autor fomentou a complexa teoria do espaço geográfico, a qual oferece até os dias atuais, suporte teórico-metodológico para as análises dos usos e relações distintas que recaem sobre o espaço. A teoria do espaço geográfico é foco para este estudo, e por isso está exposta em detalhes na sequência desta produção.

Assim sendo, relata-se que este artigo busca identificar a representatividade da teoria do espaço geográfico, de autoria do renomado geógrafo brasileiro Milton Santos, no que se refere ao fornecimento de elementos teórico-metodológicos para a estruturação dos estudos (teses e dissertações) que abordam o turismo como tema de pesquisa, no âmbito dos programas de pós-graduação stricto sensu em Geografia no Brasil.

Justifica-se que a seleção da teoria do espaço geográfico de Milton Santos está fundamentada no seu reconhecimento no âmbito brasileiro. Reconhece-se que as obras do aludido geógrafo são referências para os programas brasileiros de pós-graduação stricto sensu em Geografia, independente de suas áreas de concentração e linhas de pesquisa. Sublinha-se também que Milton Santos é uma das principais referências brasileiras no campo da Geografia, com significativo alcance internacional. Este estudo também se justifica, diante da efetiva possibilidade da referida teoria ser aplicada em pesquisas aonde o estudo do espaço é fundamental, como é o caso do turismo (Albach e Gândara, 2011).

Por considerar o turismo como um fenômeno socioespacial que interfere na dinâmica do espaço geográfico, ratifica-se este artigo e a necessidade de novas pesquisas na busca por ampliar o conhecimento científico que vem sendo gerado a partir da intersecção teórico-metodológica entre o turismo e a Geografia. Azevedo (2013) destaca o turismo como uma relevante peça de composição do conjunto sistemático e relacional de fluxos e materialidades, sendo ele capaz de produzir alterações espaciais relevantes que se transformam em desdobramentos diretos para a atuação da ciência geográfica. 
A razão que explica o direcionamento da análise para as teorias empregadas nos estudos levantados, origina-se da compreensão do importante papel que a teoria desempenha na estruturação das pesquisas científicas. Sem o emprego correto da teoria corre-se o risco de analisar os problemas de forma isolada, a partir de entendimentos subjetivos, palpites e aparências, elementos díspares do caráter científico que deve haver nos estudos acadêmicos de pós-graduação (teses e dissertações).

Quando se pondera sobre a seleção do empírico, fundamenta-se na ideia de que a produção acadêmica de maior expressão científica no cenário brasileiro é a fomentada no âmbito da pós-graduação. Teses e dissertações são entendidos como estudos que apresentam escopos mais amplos e de refinamento científico, saldo das exigências teórico-metodológicas.

Por fim, o empenho deste estudo dedica-se a ampliação dos subsídios que tratam da relação entre o turismo e a Geografia, destacando possíveis elementos teórico-metodológicos de estruturação para pesquisas científicas, a partir do emprego da teoria do espaço geográfico de Milton Santos, nos estudos (teses e dissertações) produzidos no âmbito dos programas brasileiros de pós-graduação stricto sensu em Geografia.

\section{FUNDAMENTAÇÃO TEÓRICA}

A construção de qualquer teoria parte da reunião de elementos científicos dotados de observações, ideias e postulados que legitimam uma explicação a respeito de um determinado fenômeno. Assim, a teoria é um "modelo explicativo de um fenômeno, ou conjunto de fenômenos [...] apresentando hipóteses organizadas que através de sua verificação, confirmação ou correção, visam explicar uma realidade determinada. Refere-se ao conhecimento puro, chamado de empírico" (Sposito, 2004, p.58-59).

Sabendo disso, entende-se que as teorias surgem em meio aos questionamentos que o empírico apresenta, e se dedicam a explicação de uma realidade e/ou campo temático específico. Toda teoria é o alicerce que fundamenta de forma lógica, os diferentes subsídios racionais de determinado objeto e/ou situação (observações, descrições, ideias, testes, monitoramentos e condições) possibilitando uma unidade explicativa a partir de uma variedade de dados (Vitte, 2009).

Reconhece-se que diversas teorias marcam o histórico da sistematização científica do conhecimento geográfico, sempre norteando-se na busca por explicações racionais dos fenômenos que ocorrem no e/ou através do espaço geográfico. Deste modo, diante do expressivo quantitativo de teorias geográficas, aborda-se de forma central nesta seção sobre a teoria do espaço geográfico, formatada a partir do esforço intelectual do destacado geógrafo brasileiro Milton Santos.

A primeira particularidade dessa teoria diz respeito à apreensão das peculiaridades dos países do hemisfério sul, já demonstrando resistência para análises que centralizam atenção no mundo desenvolvido do norte (baseadas nos parâmetros franceses). Milton Santos evidenciava que seu empenho teórico-metodológico centralizava-se na busca por um caráter universal, sendo então capaz de ser empreendido em qualquer espaço do mundo (Dantas, 
2014). Identifica-se um longo processo construtivo e de amadurecimento referente ao conceito do espaço geográfico e a formatação de sua teoria.

Mapeando desde obra $O$ trabalho do geógrafo no terceiro mundo (1978), e passando por outras como: $O$ espaço dividido: os dois circuitos da economia urbana (1979); Por uma geografia nova (1983); Espaço e método (1985); Metamorfoses do espaço habitado (1988), até chegar ao ponto mais alto de sua produção científica, com a obra $A$ natureza do espaço (1996), é notória a dedicação de Milton Santos em fornecer um suporte teórico-metodológico consistente para a definição do objeto de estudo da Geografia e proposição de sua teoria.

Valorizam-se igualmente as atualizações e a continuidade das análises de Milton Santos, reconhecendo a obra Brasil: território e sociedade no início do século XXI (2001) como mais um canal de aplicabilidade dos pressupostos científicos em torno do conceito de espaço geográfico e de sua teoria. Neste livro, o referido autor une-se a Maria Laura Silveira para trazer ao debate questões específicas sobre o território brasileiro, deixando um legado explicativo do espaço geográfico brasileiro, avaliado através de sua história, política, economia, infraestruturas, enfim, enquanto totalidade.

Por meio destas informações, atesta-se o fomento de uma teoria geográfica com nuances de uma teoria social do espaço, onde o homem, sua produção e o tempo se mescla diante da relação estabelecida entre teoria e empiria (Moreira, 2014). A partir deste ponto dá-se início a uma leitura específica da teoria do espaço geográfico, pontuando alguns dos seus aspectos basilares (conceitos, elementos, noções e categorias de análise), amarrados pela teia da totalidade, como se pode observar na Figura 1.

Figura 1. Principais elementos, noções e conceitos da teoria do espaço geográfico

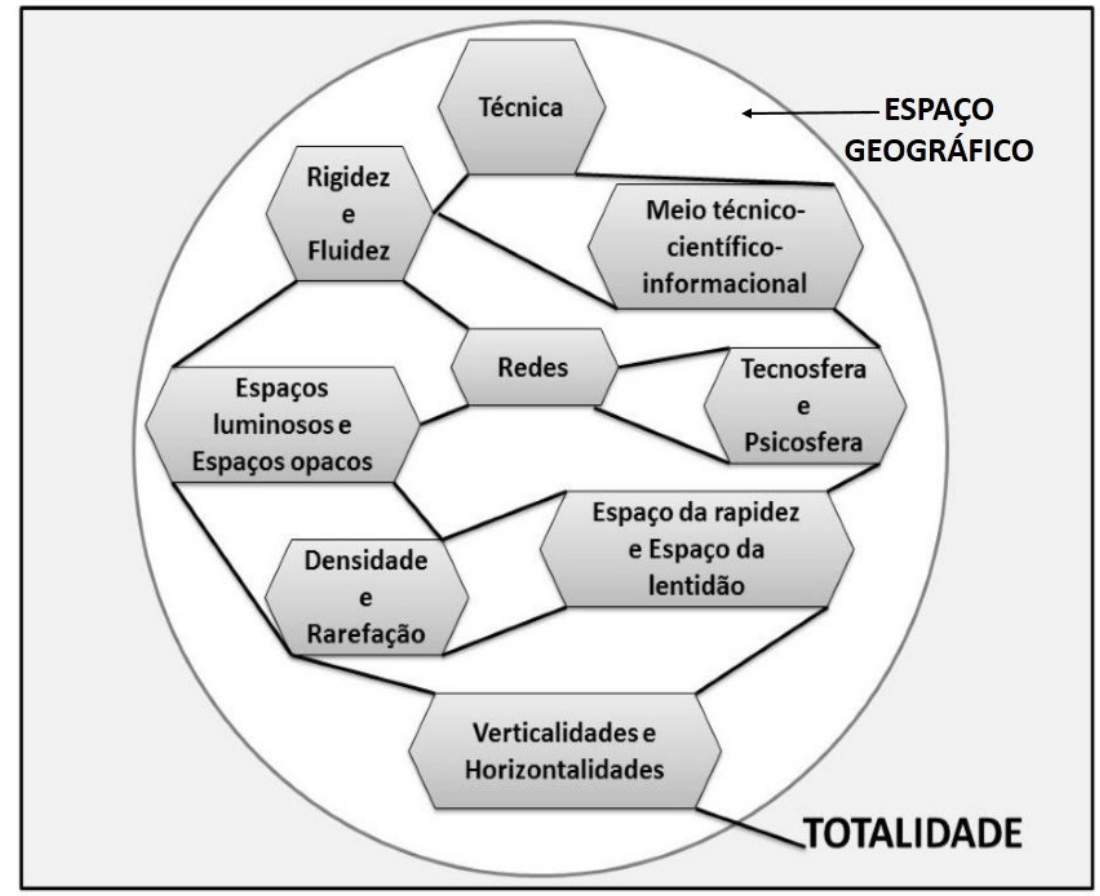

Fonte: Elaborado pelos autores com base em Santos (2009). 
Diante da Figura 1, nota-se uma significativa imbricação do conceito de espaço geográfico na composição da referida teoria, destacando o alinhamento existente entre a produção científica em torno da Geografia e as especificidades do seu objeto de estudo. Observa-se nas entrelinhas do conceito de espaço geográfico proposto por Milton Santos, à coexistência de uma infinidade de elementos, noções, normas e conceitos auxiliares, e que sinergicamente compactam o alicerce da teoria do espaço geográfico.

Para Santos (2009, p.63) o espaço geográfico é "um conjunto indissociável, solidário e também contraditório, de sistemas de objetos e sistemas de ações, não considerados isoladamente, mas como o quadro único no qual a história se dá". Como base neste conceito, segue a análise dos principais elementos que dão sustentação à aludida teoria e que foram igualmente representados na Figura 1.

Inicialmente reconhece-se que associado ao entendimento relacional entre os sistemas de objetos e os sistemas de ações, tão marcante no conceito de espaço geográfico, está à compreensão do papel que as técnicas desempenham.

Na gênese do espaço geográfico localiza-se uma estreita conexão entre os diferentes elementos, a técnica e o tempo, permitindo alterações nos espaços. Assim, a técnica surge como um elemento basilar para a análise do espaço, uma vez que ela permite elucidar o próprio espaço e sua periodização. Santos (2009, p.54) diz que:

Tempo, espaço e mundo são realidades históricas [...] O ponto de partida é a sociedade humana realizando-se. Essa realização se dá sobre uma base material: a materialidade e suas diversas formas; as ações e suas diversas feições. Assim empiricizamos o tempo, [...] e desse modo assimilamos ao espaço, que não existe sem a materialidade. A técnica entra aqui como um traço de união. [...] É por intermédio das técnicas que o homem, no trabalho, realiza essa união entre espaço e tempo.

Entende-se, portanto, que a técnica reveste-se de características que a expõem como um importante elemento histórico de transformação e compreensão dos espaços, e a sua evolução responde às necessidades básicas que visam à sobrevivência e o pleno desenvolvimento dos sujeitos, gerando dinâmicas que modificam os espaços constantemente. A descoberta de uma nova técnica agita a transformação/produção do meio geográfico, do mesmo modo que modifica as condições de organização social e geográfica dos sujeitos, originando novas especializações, usos e intencionalidades (Santos, 2009).

Como desdobramentos do fomento das técnicas surgem às noções de rigidez e fluidez. Entende-se que as técnicas não se desenvolvem similarmente pelo território, uma vez que nem todos os territórios estão aptos a manuseá-las, e por essa razão acabam tornando-se exclusivas para alguns espaços.

Entende-se que a noção de rigidez caminha paralela com a compreensão de retenção dos fluxos fomentados pelo desenvolvimento das técnicas, assim como a ideia de fluidez direciona-se para o livre escoamento desses fluxos originados pelos usos de técnicas especificas. Estes cenários geram a ideia de intencionalidade programada, que norteia a produção dos 
lugares para usos predeterminados, fomentando a segregação resultante da ação conjugada entre ciência, técnica, capital e poder.

Assim, diante da modificação do meio geográfico, em função da atuação de técnicas diversas, surge o conceito denominado por Santos (2009) de meio técnico-científico-informacional (MTCl), que igualmente fornece subsídios para a composição da teoria do espaço geográfico, por encontrar-se associado a uma série de elementos e noções que se articulam com o próprio espaço.

Observa-se que como saldo do desenvolvimento das técnicas ocorre uma mutação do meio natural que se transforma em um meio artificializado, repleto de instrumentos que atestam o avanço das técnicas, da ciência e da informação. É desta união que surgem processos sociais diversos e espaços cada vez mais equipados, favorecendo novas intencionalidades e a circulação de capital, pessoas e conhecimento.

Como meio natural entende-se o período em que a relação do homem com o meio ocorria sem grandes alterações. Com a ascensão das técnicas, inicia-se uma inédita diferenciação de áreas com base na expansão e quantificação de objetos técnicos, em substituição aos objetos, antes naturais. Um marco importante neste tempo é o surgimento do comércio (Santos, 2009).

Sabe-se que o advento do MTCl só ocorre após a Segunda Guerra Mundial (1939-1945), e firma-se durante os anos 1970. Esse meio diferencia-se dos já citados por trazer consigo a interação simultânea entre ciência, tecnologia e informação. Nesta conjuntura, os objetos além de técnicos passam a ser informacionais e dotados de intencionalidades que interferem na produção, utilização e funcionamento do próprio espaço (Santos, 2004).

Constata-se uma requalificação dos espaços, com vistas a acatar os interesses dos agentes hegemônicos diante de um sistema mundial cada vez mais tecnificado. Por essa razão, Santos (2009, p. 239) afirma que "o meio técnico-científico-informacional é a cara geográfica da globalização".

Ainda com relação ao $\mathrm{MTCl}$, reforça-se a ideia de que a informação é vista como um recurso que está a serviço dos agentes hegemônicos, e que determina o processo que movimenta as transformações do espaço, configurando-se como um vetor para ações que definem as desigualdades espaciais. Identifica-se que a informação induz territórios a se equiparem de objetos que facilitem a sua circulação, atestando que os espaços que não conseguem se equipar são postos à margem do processo.

Atreladas ao conceito de $\mathrm{MTCl}$ estão às noções da tecnosfera e psicosfera. Entendidas aqui como as colunas pelas quais o $\mathrm{MTCl}$ introduz questões que tratam de racionalidade, irracionalidade e contrarracionalidade no espaço (Santos, 2009). A tecnosfera é a interface que contém os preceitos que estão voltados para a produção, comércio e interesses externos, os quais conferem a aparência de uma prótese indiferente ao espaço local. Já sobre psicosfera, sabe-se que ela atua no campo das ideias e crenças, representadas por revoluções. Observa-se a tecnosfera sendo composta pela articulação dos agentes hegemônicos na tomada de decisão, ao passo que na psicosfera se localiza o confronto das intenções dos agentes, e por isso o surgimento de diferentes racionalidades, com destaque para os interesses dos agentes locais. 
Prosseguindo com o debate de formatação da teoria do espaço geográfico, coloca-se na discussão o conceito de redes que são compreendidas como meios e/ou mecanismos que asseguram a circulação dos elementos que geram a informação. A princípio, as redes são analisadas apenas pela aparência e realidade material que detêm, sendo definidas como infraestruturas que possibilitam o transporte de matéria, energia e informação, firmando-se em um espaço dotado de pontos de acesso, arcos de transmissão e nós de comunicação. De outro modo, é possível entender as redes como elementos sociopolíticos compostos por pessoas, mensagens e valores inseridos na mesma perspectiva de unificação por meio de conjunturas determinadas (Santos, 2009).

A discussão das redes aqui não é a de simples ocupação das áreas. Busca-se possibilitar novos canais de ligação e comunicação entre os pontos materiais espacializados em territórios distantes, estimulados por uma meta de viés econômico. Por isso Santos (2009, p. 265) diz que "quanto mais avança a civilização material, mas se impõe o caráter deliberado na constituição de redes".

No entanto, mesmo com a utilização das redes para facilitar a troca de informações, inexiste um alcance homogêneo, visto que esses instrumentos facilitam a transmissão desses dados apenas para territórios aptos pela fluidez e tecnosfera, fato que associa o sentido existencial das redes com questões de poder e controle, refletindo novas diferenciações espaciais.

Ainda pautando-se no parâmetro da informação é permitido, com base na teoria do espaço geográfico, adjetivar os espaços enquanto luminosos e opacos. Compreendem-se como espaços luminosos, os que detêm a posse e o controle da informação, e que por isso acumulam conteúdos informacionais, habilitando-se em função da captação de atividades econômicas, capital, tecnologia e organização. Já os espaços onde essas características são frágeis passam a ser denominados de opacos, uma vez que o brilho, ligado à posse da informação, incide em menor intensidade e de forma inconstante.

Dito isto, enfatiza-se que os espaços luminosos são os que mais acumulam densidades técnicas e informacionais, atraindo atividades de expressivo investimento de capital, tecnologia, informações e valores organizacionais. Estes espaços acabam obedecendo aos interesses das empresas que os dirigem verticalmente, implicando na ingovernabilidade dos lugares (Santos e Silveira, 2001). Já os espaços opacos por sua vez, não conseguem chamar atenção de investidores justamente por não disporem de informação, técnicas, e com isso, de confiabilidade para investimento mercadológico.

Alinhadas a essa nova qualificação espacial, também estão às noções de densidade e rarefação, caracterizadas como elementos dialéticos que igualmente dão suporte ao entendimento da teoria do espaço geográfico. Pensar sobre densidade é o mesmo que falar de uma espessa oferta de técnicas e informações, ponderando sobre uma maior ou menor densidade de próteses, leis e normas reguladoras da vida coletiva, ou seja, no controle do maior ou menor uso da informação. Já quando se pensa em rarefação, associa-se a noção de uma densidade reduzida. Nota-se uma construção de pares dialéticos, onde os espaços densos estão conexos aos espaços luminosos, assim como os espaços rarefeitos estão atrelados aos espaços opacos (Santos e Silveira, 2001). 
De forma concatenada ainda é possível inserir as noções de espaços da rapidez e espaços da lentidão. É perceptível a lógica do autor em organizar suas ideias por meio de associações dialéticas que se complementam e se fundem no plano espacial. Milton Santos percebe o espaço da rapidez como reflexo do ato de dar ordens e de liderar o território, deixando para o espaço da lentidão a função de assimilar e obedecer às normas postas. Essa seletividade espacial insere questões na divisão territorial do trabalho, visto que as empresas maiores buscam espaços que Ihes garantam otimização do lucro, deixando para firmas de potencial moderado, as sobras espaciais, que em sua maioria são opacas e rarefeitas (Santos, 2009).

Ao continuar com a exposição, chega-se aos conceitos de verticalidades e horizontalidades. De forma didática, Santos (2009, p. 286) diz que as: "verticalidades são vetores de uma racionalidade superior dos setores hegemônicos, que criam um cotidiano obediente e disciplinado. E as horizontalidades é o lugar da contrafinalidade, localmente gerada. Onde simultaneamente é o lugar da complacência e/ou da revolta".

Entende-se que a contemporaneidade está fortemente marcada por relações verticais, onde os vetores da modernização acabam causando desordem onde se instalam e/ ou arbitrando uma ordem em benefício próprio e estranha à localidade. Contudo, por meio das contrafinalidades que surgem diante do processo vertical, é possível cooperar com ações horizontais localmente concebidas e que ampliam a coesão da sociedade civil, em função da coletividade.

Pontua-se que o Estado e o Mercado são agentes hegemônicos que produzem decisões verticalizadas e intencionais. E na contramão disso, nota-se que as horizontalidades emergem da população residente no local e que busca intervir na supremacia hegemônica, visando decisões coletivas. Pensando assim, horizontalidades e verticalidades são recortes espaciais superpostos, condicionados e condicionantes da solidariedade organizacional (Santos, 1994).

Diante do cenário que vem sendo exposto, fica evidente a necessidade da noção de totalidade, com a missão de aglutinar todos os elementos, conceitos e outras noções já citadas, e que estão presentes na base da teoria do espaço geográfico. Esses elementos também têm significado fora da totalidade, mas nesse contexto de movimento transformador do espaço, eles só conseguem fazer sentido por meio da associação com os demais componentes. É notório que a relação é tão estreita que se torna difícil identificá-los, e exemplificá-los separadamente.

Visando um alinhamento adequado é importante ultrapassar a ideia de que a totalidade seja uma simples somatização de elementos distintos que mesmo isolados dão conta de explicar um panorama geral. Contrário a isso, tem-se que a totalidade é quem consegue abarcar o funcionamento das partes que a compõem, "eis porque se diz que o todo é maior que a soma de suas partes" (Santos, 2009, p.116).

Entende-se que a totalidade resulta de totalizações, ou seja, de um processo de constantes modificações. Visualiza-se uma progressão infinita de possibilidades em que o movimento dos elementos impõe a necessidade de novos elementos, os quais modificam os aspectos passados, lançando novas características e fornecendo uma nova sequência ao ciclo. Somente através do movimento do conjunto é que se pode corretamente valorizar cada parte e analisá-las, para na sequência reconhecer o todo. Se a análise considerar os elementos 
individualmente como todos independentes, múltiplas possibilidades da interação podem ser descartadas (Santos, 1988).

Atesta-se que a totalidade direciona a análise proposta pela teoria do espaço geográfico para uma preocupação teórico-metodológica com a história das relações e dos objetos por meio dos quais as ações humanas tornam-se possíveis. "Impõe-se na análise, apreender objetos e relações como um todo, e só assim estaremos perto de ser holistas, isto é, gente preocupada com a totalidade" (Santos, 1988, p.19-20).

Por toda exposição, reconhece-se a complexidade da teoria do espaço geográfico. Chama-se atenção para o nível de concatenação de todos os subsídios mencionados sob a mesma plataforma da totalidade espacial. Ao continuar com a exposição, chega-se ao processo metodológico responsável pela roteirização, construção e operacionalização deste artigo.

\section{METODOLOGIA}

Uma seleção adequada de procedimentos metodológicos é de fundamental importância para o alcance de um suporte técnico-científico que permita a articulação do pensamento, sinalizando para um caminho interpretativo. Considerando isto, segue a explanação dos subsídios metodológicos que operacionalizaram a questão proposta.

Ao ponderar sobre a tipologia do estudo, relata-se que este se caracteriza como exploratório-descritivo devido o reconhecimento do turismo como um campo de estudo recente, razão que associa o ato de explorar com o ato de descrever, visando firmar um arcabouço informacional sobre o conteúdo presente no cerne da pesquisa (Veal, 2011). Sobre a postura exploratória é possível citar o uso de ferramentas técnicas como o levantamento bibliográfico (Gonçalves, 2005) que forneceu expertises no momento da análise dos dados.

No que se refere ao objeto da pesquisa, destaca-se o viés qualitativo, em função da análise se pautar em quesitos como: tipologias de teorias, usos e subjetividades presentes nos estudos (teses e dissertações) sobre o turismo, produzidos pelos programas brasileiros de pós-graduação stricto sensu em Geografia. Richardson (2008) pontua que a tipologia qualitativa justifica-se pela busca do entendimento da natureza de um tipo de conhecimento já produzido.

Similar a isso, informa-se que dados quantitativos também marcam presença na categorização do empírico, servindo como complemento para as análises finais. Gil (2011) afirma que é permitido para uma abordagem qualitativa, o uso de análises estatísticas para ampliar suas conclusões.

Sobre a seleção do empírico, relata-se que ela foi realizada com o suporte da Coordenação de Aperfeiçoamento de Pessoal de Nível superior (Capes), por meio de um levantamento de teses e dissertações depositadas pelos programas brasileiros de pós-graduação stricto sensu em Geografia, no banco digital de teses e dissertações da Plataforma Sucupira, entre o segundo semestre do ano de 2016 e primeiro semestre do ano de 2017.

O inventário dos estudos foi solicitado a Capes devido a sua abrangência, no que tange à coleta e armazenamento de teses e dissertações no âmbito brasileiro. Uma vez que todas as 
pesquisas catalogadas no seu banco digital são fornecidas pelos próprios programas de pós-graduação do Brasil, por meio de um sistema denominado de Coleta até o ano de 2014, que atualmente é nomeado de Plataforma Sucupira. Assim, foi permitido garantir a seguridade no que se refere à ampla participação dos programas brasileiros de pós-graduação stricto sensu em Geografia avaliados e conceituados pela referida agência brasileira de fomento científico.

A norma que validou os estudos como parte do empírico deste artigo foi à identificação nos títulos e resumos das seguintes palavras-chaves: turismo, atividade turística e fenômeno turístico. A escolha desses termos está condicionada ao caráter dual do turismo. Ou seja, o turismo sendo compreendido como um vetor de produção do capital, associado à noção de atividade turística, e/ou o turismo sendo apreendido como vetor de desenvolvimento, adjetivado de fenômeno social (Castro, 2006).

O levantamento dos estudos (teses e dissertações) que optam pelo turismo como tema de pesquisa, no âmbito dos programas brasileiros de pós-graduação stricto sensu em Geografia possibilitou a confecção da Tabela 1, que destaca dentre os 65 programas brasileiros de pós-graduação stricto sensu em Geografia validados pela Capes, somente os programas que fomentaram estudos com base na relação estabelecida com a temática do turismo, seguido pela quantidade de estudos e suas tipologias.

Tabela 1. Quantitativo de estudos (teses e dissertações) no âmbito dos programas brasileiros de pós-graduação stricto sensu em Geografia que optam pela temática do turismo

\begin{tabular}{|c|c|c|c|c|}
\hline \multirow{2}{*}{ REGIÃO } & \multirow{2}{*}{ IES } & \multicolumn{3}{|c|}{ QUANTIDADE } \\
\hline & & D & $\mathbf{T}$ & Total \\
\hline \multirow{3}{*}{ Norte } & 01-Universidade Federal do Pará & 13 & - & 13 \\
\hline & 02-Fundação Universidade Federal de Rondônia. & 03 & - & 03 \\
\hline & Total de Trabalhos - Região Norte & 16 & - & 16 \\
\hline \multirow{8}{*}{ Nordeste } & 03-Universidade Federal da Bahia & 26 & - & 26 \\
\hline & 04-Universidade Federal do Ceará & 21 & 02 & 23 \\
\hline & 05-Universidade Estadual do Ceará & 35 & - & 35 \\
\hline & 06-Universidade Federal da Paraíba & 07 & - & 07 \\
\hline & 07-Universidade Federal de Pernambuco & 32 & 03 & 35 \\
\hline & 08-Universidade Federal do Rio Grande do Norte & 25 & - & 25 \\
\hline & 09-Fundação Universidade Federal de Sergipe & 15 & 10 & 25 \\
\hline & Total de Trabalhos - Região Nordeste & 161 & 15 & 176 \\
\hline \multirow{6}{*}{ Centro-oeste } & 10-Universidade de Brasília & 12 & - & 12 \\
\hline & 11-Universidade Federal de Goiás & 28 & 04 & 32 \\
\hline & 12-Fundação Universidade Federal de Mato Grosso do Sul & 15 & - & 15 \\
\hline & 13-Universidade Federal da Grande Dourados & 04 & - & 04 \\
\hline & 14-Universidade Federal de Mato Grosso & 21 & - & 21 \\
\hline & Total de Trabalhos - Região Centro-Oeste & 80 & 04 & 84 \\
\hline
\end{tabular}




\begin{tabular}{|c|c|c|c|c|}
\hline \multirow{13}{*}{ Sudeste } & 15-Universidade Federal de Minas Gerais & 37 & 02 & 39 \\
\hline & 16-Universidade Federal de Uberlândia & 24 & 04 & 28 \\
\hline & 17-Pontifícia Universidade Católica de Minas Gerais & 11 & 03 & 14 \\
\hline & 18-Universidade Federal do Rio de Janeiro & 16 & 16 & 32 \\
\hline & 19-Universidade Federal Fluminense & 09 & 05 & 14 \\
\hline & 20-Universidade Estadual do Rio de Janeiro & 24 & - & 24 \\
\hline & 21-Pontifícia Universidade Católica do Rio de Janeiro & 02 & - & 02 \\
\hline & 22-Universidade de São Paulo & 71 & 54 & 125 \\
\hline & 23-Universidade Estadual de Campinas & 22 & 08 & 30 \\
\hline & 24-Pontifícia Universidade Católica de São Paulo & 04 & - & 04 \\
\hline & 25-Universidade Estadual P. Júlio de Mesquita Filho & 32 & 34 & 66 \\
\hline & 26-Universidade Federal do Espírito Santo & 01 & - & 01 \\
\hline & Total de Trabalhos - Região Sudeste & 253 & 126 & 379 \\
\hline \multirow{10}{*}{ Sul } & 27-Universidade Federal do Paraná & 34 & 13 & 47 \\
\hline & 28-Universidade Estadual de Londrina & 10 & - & 10 \\
\hline & 29-Universidade Estadual de Maringá & 12 & 01 & 13 \\
\hline & 30-Universidade Estadual de Ponta Grossa & 05 & - & 05 \\
\hline & 31-Universidade Estadual do Oeste do Paraná & 02 & - & 02 \\
\hline & 32-Universidade do Rio Grande do Sul & 13 & 04 & 17 \\
\hline & 33-Universidade Federal de Santa Maria & 10 & - & 10 \\
\hline & 34-Universidade Federal do Rio Grande & 01 & - & 01 \\
\hline & 35-Universidade Federal de Santa Catarina & 44 & 10 & 54 \\
\hline & Total de Trabalhos - Região Sul & 131 & 28 & 159 \\
\hline \multicolumn{2}{|r|}{ Total Geral } & 641 & 173 & 814 \\
\hline
\end{tabular}

Fonte: Elaborado pelos autores (2017). Legenda: D- Dissertações; T- Teses.

Com base nos dados expostos na Tabela 1 é possível verificar um significativo montante de 814 estudos produzidos pelos programas brasileiros de pós-graduação stricto sensu em Geografia, que se dedicam a temática do turismo. Desse quantitativo, 641 estudos são dissertações e 173 são teses. Evidencia-se a representatividade da temática do turismo nos estudos geográficos (teses e dissertações) do âmbito da pós-graduação stricto sensu no Brasil.

Fazendo a devida leitura da Tabela 1, observa-se que as pesquisas distribuem-se por 35 Instituições de Ensino Superior (IES), de um total de 51 instituições que ofertam a pós-graduação em Geografia no Brasil. Pontua-se que dos 65 programas de pós-graduação existentes na época do levantamento, 44 deles apresentam conectividade com o turismo $(67,70 \%)$ e 21 programas $(32,30 \%)$ não apresentaram nenhum estudo sobre o turismo.

Também é permitido destacar a relevância da produção científica na região sudeste do Brasil, onde localiza-se o maior montante de estudos (379), distribuídos por instituições de alcance internacional, como é o caso da Universidade de São Paulo (USP). A região nordeste aparece em segundo lugar, com relação ao número de estudos levantados (176), destacando a potencialidade turística do nordeste brasileiro, que apresenta mais de $8.000 \mathrm{~km}^{2}$ de litoral, 
impulsionando o fomento de pesquisas sobre o turismo, uma vez que o segmento sol e praia lidera a motivação dos turistas internacionais que chegam ao Brasil. (Brasil, 2018).

Ao definir o universo da pesquisa, logo se viu a necessidade em realizar um cálculo amostral, a fim de fornecer didática para as etapas de operacionalização e exposição de resultados. Diante de uma consultoria especializada em estatística, e com base nas proposições de Pires (2008), foi selecionada a amostragem aleatória estratificada com alocação proporcional para nortear a coleta, e por entender que a representatividade de cada estrato da amostra seria proporcional a sua representatividade dentro do universo da pesquisa.

Informa-se que antes da aplicação das fórmulas estatísticas foi feita a leitura e numeração de todos os 814 títulos e resumos, visando estimar a proporção de trabalhos que apresentavam o turismo como temática central e/ou como temática secundária de estudo. Identifica-se que em alguns trabalhos o turismo apareceu de forma estruturante para a pesquisa (temática central), e em outros casos a temática do turismo era apenas uma consequência ocasional da discussão central levantada pelo estudo.

De posse desses dados, estimou-se a quantidade de estudos por IES, considerando para o cálculo da amostra apenas os estudos que analisavam o turismo como temática central. Logo, para determinar o tamanho da amostra estratificada com alocação proporcional, foram utilizadas as fórmulas que seguem.

$$
\text { Fórmula (01): } n=\frac{\frac{1}{N} \sum_{h=1}^{H} N_{h} S_{h}^{2}}{V+\frac{1}{N^{2}} \sum_{h=1}^{H} N_{h} S_{h}^{2}}
$$

Onde:

$\mathrm{N}$ - tamanho do universo da pesquisa;

$N_{h}$ - tamanho de cada estrato do empírico;

$S_{h}^{2}$ - variância de cada estrato;

$$
V=\left(\frac{e}{Z_{\alpha}}\right)^{2} \text { é o erro dividido pela significância. }
$$

A expectativa de erro foi de $13 \%$ e a significância de $5 \%$. Valores entendidos como adequados para a tipologia da pesquisa. Como a alocação foi proporcional tem-se que para cada estrato, o tamanho da amostra é calculado pela seguinte equação:

Fórmula (02): $n_{h}=\frac{N_{h}}{N} \times n$

Já quando se considera a margem sobre o erro amostral, esta foi calculada a partir da seguinte equação: Fórmula (03): $P\left(\left|\bar{y}-\bar{y}_{U}\right|<e\right)=1-\alpha^{(3)}$. Onde: $\bar{y}$ é a média amostral, e $\bar{y}_{U}$ é a média populacional, também representada pela letra grega $\mu$. Como resultado desses cálculos elaborou-se a Tabela 2, que consta com o tamanho da amostra por região. 
Tabela 2. Amostra estratificada por região e por IES

\begin{tabular}{|c|c|c|c|c|c|}
\hline \multirow{3}{*}{ Norte } & IES & T.C & T.S & T.P & A.IES \\
\hline & UFPA & 11 & 2 & 13 & 1 \\
\hline & UNIR & 2 & 1 & 3 & 0 \\
\hline \multicolumn{2}{|c|}{ Total por região } & 13 & 3 & 16 & 1 \\
\hline \multirow{7}{*}{ Nordeste } & UFBA & 18 & 8 & 26 & 2 \\
\hline & UFC & 12 & 11 & 23 & 1 \\
\hline & UECE & 17 & 18 & 35 & 2 \\
\hline & UFPB & 4 & 3 & 7 & 1 \\
\hline & UFPE & 26 & 9 & 35 & 2 \\
\hline & UFRN & 20 & 5 & 25 & 1 \\
\hline & FUFSE & 12 & 13 & 25 & 1 \\
\hline \multicolumn{2}{|l|}{ Total por região } & 109 & 67 & 176 & 10 \\
\hline \multirow{5}{*}{ Centro-Oeste } & UNB & 9 & 3 & 12 & 1 \\
\hline & UFG & 19 & 13 & 32 & 2 \\
\hline & UFMS & 14 & 1 & 15 & 1 \\
\hline & UFGD & 2 & 2 & 4 & 0 \\
\hline & UFMT & 19 & 2 & 21 & 1 \\
\hline \multicolumn{2}{|l|}{ Total por região } & 63 & 21 & 84 & 5 \\
\hline \multirow{12}{*}{ Sudeste } & UFMG & 31 & 8 & 39 & 2 \\
\hline & UFU & 18 & 10 & 28 & 2 \\
\hline & PUC-MG & 8 & 6 & 14 & 1 \\
\hline & UFRJ & 19 & 13 & 32 & 2 \\
\hline & UFF & 7 & 7 & 14 & 1 \\
\hline & UERJ & 9 & 15 & 24 & 1 \\
\hline & PUC-RJ & 1 & 1 & 2 & 0 \\
\hline & USP & 73 & 52 & 125 & 8 \\
\hline & UNICAMP & 16 & 14 & 30 & 2 \\
\hline & PUC-SP & 1 & 3 & 4 & 0 \\
\hline & UNESP & 39 & 27 & 66 & 4 \\
\hline & UFES & 1 & 0 & 1 & 0 \\
\hline \multicolumn{2}{|l|}{ Total por região } & 223 & 156 & 379 & 23 \\
\hline \multirow{9}{*}{ Sul } & UFPR & 30 & 17 & 47 & 3 \\
\hline & UEL & 5 & 5 & 10 & 1 \\
\hline & UEM & 8 & 5 & 13 & 1 \\
\hline & UEPG & 4 & 1 & 5 & 0 \\
\hline & UNIOESTE & 1 & 1 & 2 & 0 \\
\hline & UFRGS & 10 & 7 & 17 & 1 \\
\hline & UFSM & 5 & 5 & 10 & 1 \\
\hline & FURG & 0 & 1 & 1 & 0 \\
\hline & UFSC & 20 & 34 & 54 & 3 \\
\hline \multicolumn{2}{|c|}{ Total por região } & 83 & 76 & 159 & 10 \\
\hline \multicolumn{2}{|c|}{ Total Geral } & 491 & 323 & 814 & 49 \\
\hline
\end{tabular}

Fonte: Elaborado pelos autores (2017); IES: Instituição de Ensino Superior; T.C: Temática central T.S: Temática secundária; T.P: Total de produções; A.IES: Amostra por Instituição de Ensino superior. 
Após a definição numérica da amostra, iniciou-se a etapa de seleção das unidades que seriam retiradas do universo da pesquisa para participar da análise. Esta seleção foi efetivada aplicando-se a técnica estatística dos números aleatórios.

Concluindo este processo chegou-se a um total de 49 trabalhos acadêmicos (teses e dissertações), onde 17 estudos são teses e 32 são dissertações. Informa-se que para cada trabalho foi designado um código de identificação composto por um número em ordem crescente (01-49) seguido da letra $D$, para identificar dissertações e/ou da letra $T$ para representar as teses.

Comunica-se ainda que o recorte temporal das pesquisas selecionadas para a análise compreende um intervalo entre os anos de 1985 a 2015, ou seja, 30 anos de pesquisas geográficas que estudam o turismo. Em face dessas possibilidades foi possível ter acesso às informações detalhadas de cada trabalho analisado, a saber: região, estado e IES que cada pesquisa está vinculada, como também o título, tipologia, autor, orientador e ano de defesa.

Concluída a coleta dos estudos via downloads (por meio da rede mundial de computadores) e/ou contato direto com os autores das pesquisas via correio eletrônico (e-mail), inicia-se a ordenação do material visando sua interpretação.

Para o momento das análises, partes específicas de cada trabalho da amostra foram selecionadas, a saber: resumo, sumário, introdução, objetivos e procedimentos metodológicos. A escolha desses itens alinha-se com as normativas da Associação Brasileira de Normas Técnicas (ABNT) que apontam as seguintes especificidades. No resumo, tem-se uma visão panorâmica do trabalho; no sumário encontram-se de forma organizada, os principais temas e tópicos trabalhados na pesquisa. A introdução é composta pela problemática, problema, justificativa e objetivos. Já nos processos metodológicos encontram-se as opções de teorias, categorias de análise entre outros elementos de sustentação metódica (Iskandar, 2012).

Informa-se ainda que paralelo à efetivação dessas etapas aplicou-se a técnica da análise temática que "consiste em isolar temas de um texto e extrair as partes úteis, em conformidade com as questões estudadas, permitindo sua comparação, com outros textos selecionados similarmente" (Richardson, 2008, p.197).

De modo paralelo, e por compreender a dinamicidade do ambiente da pós-graduação no Brasil, destaca-se o cenário dinâmico da pós-graduação brasileira como uma possível limitação para o estudo. Relata-se que já se espera que o levantamento realizado por esta pesquisa necessite de complementações, diante do fomento de novos programas, e consequentemente de novos estudos que versam sobre o saber geográfico acerca do turismo no Brasil.

Ainda vale ratificar, em face da exposição das técnicas e ferramentas, que o filtro principal para as devidas interpretações esteve centrado no conteúdo presente na teoria do espaço geográfico. No entanto, enfatiza-se que em nenhum momento pensou-se em elencar o conteúdo da aludida teoria como um critério normatizador para determinar ou não a geograficidade das pesquisas analisadas. $O$ empenho central motiva-se pela tentativa de identificar a representatividade da teoria do espaço geográfico na oferta de elementos para a fundamentação dos estudos geográficos que se dedicam a temática do turismo. 


\section{ANÁLISE E DISCUSSÃO DOS RESULTADOS}

Ao analisar todo suporte teórico-metodológico pensado em torno do estudo da temática do turismo, destaca-se o uso de teorias diferenciadas que refletem diretamente as distintas interfaces que o turismo, enquanto fenômeno socioespacial, promove no espaço geográfico.

Inicialmente, diante das análises dos dados coletados, é permitido ratificar a representatividade do geógrafo Milton Santos para o cenário da pós-graduação stricto sensu em Geografia no Brasil. Relata-se que 35 pesquisas (71,42 \%) de um total de 49 estudos, fizeram uso do referencial teórico proposto pelo aludido geógrafo, empregando diretamente suas distintas teorias nos estudos e/ou utilizando de suas categorias de análise, conceitos, elementos e noções para subsidiar informações especificas levantadas em torno da questão do espaço geográfico e da sua teoria.

Explica-se que esta informação não implica que todo o quantitativo fez uso exclusivo das contribuições teórico-metodológicas de Milton Santos, visto que distintas teorias, conceitos e categorias de análise foram identificadas nas pesquisas. Contudo, os autores sempre que possível, recorreram ao esforço intelectual do aludido geógrafo para explicar e/ou correlacionar alguma conjuntura expressa nos seus estudos, sobretudo os que tratavam do conceito de espaço geográfico e de sua teoria.

Feito esta ressalva, destaca-se no Quadro 01, algumas das teorias identificadas e citadas nos estudos analisados. Relata-se que as teorias foram subdivididas por suas características e por informações de seus autores, onde constam teorias chamadas de geográficas, elaboradas em meio ao avanço científico da ciência geográfica, e teorias chamadas de não geográficas que evidenciam o caráter interdisciplinar da Geografia, que possibilitou a aproximação com parâmetros científicos de ciências contiguas. 
Quadro 01. Identificação das teorias presentes nos estudos que abordam o turismo como temática de pesquisa, no âmbito da pós-graduação stricto sensu em Geografia no Brasil

\begin{tabular}{|l|l|l|}
\hline \multirow{4}{*}{$\begin{array}{c}\text { Tipologia } \\
\text { Geográficas }\end{array}$} & \multicolumn{1}{|c|}{ Nome da teoria (\%) } & \multicolumn{1}{|c|}{ Autor } \\
\cline { 2 - 3 } & Teoria do espaço geográfico (19\%) & Milton Santos \\
\cline { 2 - 3 } & Teoria dos lugares centrais (12\%) & W. Christaller \\
\cline { 2 - 3 } & Teoria dos circuitos da economia urbana (8\%) & M. Santos \\
\cline { 2 - 3 } & Teoria do geossistema (1\%) & V. B. Sochava \\
\cline { 2 - 3 } & Teoria do espaço turístico (6\%) & A.A.B. Rodrigues \\
\cline { 2 - 3 } & Teoria dos refúgios (1\%) & J. Haffer \\
\cline { 2 - 3 } & Teoria das localizações (1\%) & J. H. V. Thünen \\
\hline \multirow{5}{*}{ Geogricas } & Teoria da complexidade (6\%) & E. Morin; \\
\cline { 2 - 3 } & Teoria da produção do espaço (6\%) & H. Lèfebvre \\
\cline { 2 - 3 } & Teorias do desenvolvimento (em diferentes escalas) (10\%) & Autores diversos \\
\cline { 2 - 3 } & Teoria geral dos sistemas (12\%) & L. von Bertalanffy \\
\cline { 2 - 3 } & Teoria do espaço turístico (4\%) & R. Boullón \\
\cline { 2 - 3 } & Teoria do ciclo de vida das destinações turísticas (4\%) & R.W. Butler \\
\cline { 2 - 3 } & Teoria da ação comunicativa (1\%) & J. Habermas \\
\cline { 2 - 3 } & Teoria dos signos (1\%) & C. Morris \\
\cline { 2 - 3 } & Teoria da motivação (1\%) & A. H. Maslow \\
\cline { 2 - 3 } & Teoria do Marketing dos lugares (4\%) & P. Kotler \\
\hline
\end{tabular}

Fonte: Elaborado pelos autores (2017).

Diante da categorização, a análise prontamente confirma a liderança da teoria do espaço geográfico para os estudos (teses e dissertações) que abordam o turismo como temática central de pesquisa, no âmbito da pós-graduação stricto sensu em Geografia no Brasil. Destaca-se que a referida teoria forneceu sustentação teórico-metodológica para $19 \%$ das pesquisas avaliadas, e a partir dessa comprovação é permitido pontuar observações.

É nítido que o uso da teoria do espaço geográfico por essas pesquisas está motivado diretamente pela compreensão relacional dos sistemas de objetos e dos sistemas de ações que cercam a atividade do turismo, por meio de suas formas (infraestrutura urbana básica e infraestrutura especializada para o turismo), funções (vendas de produtos e pacotes turísticos, captação de fluxos, estímulo à competitividade e inovação mercadológica entre outras), estruturas (Posicionamento do Estado, secretarias municipais e estaduais, fomento de políticas públicas de turismo, planos de turismo, atuação do Ministério do turismo) e processos (relação global e local; visitante e local, e impactos de todas às ordens). Observa-se que todos estes subsídios balizam o conceito de espaço geográfico, e simultaneamente estruturam a teoria do espaço geográfico de Milton Santos, podendo ser localizados nos debates sobre o turismo.

Nota-se que estes elementos possibilitam a espacialização turística (auxiliados pelos avanços técnicos), compondo e alterando simultaneamente os espaços, e inserindo inúmeras dinâmicas que permitem a efetivação da vida dos sujeitos, ao passo que também estimulam 
a produção de novos espaços alinhados com a praxe turística repleta de intencionalidades distintas.

Fica nítido que é por intermédio da técnica que se estabelece a afinidade entre o homem e o meio (natural ou modificado pelo homem), e como consequência torna-se possível aos sujeitos concretizarem sua vida, por meio de novos espaços e/ou modificando os já existentes por motivos diversos, inclusive a motivação pelo turismo (seja pela viagem e/ou pelo fomento).

Percebe-se nos estudos, o turismo como uma prática que agrega novas possibilidades técnicas de aperfeiçoamento dos serviços prestados, provando a inerente relação entre o homem e o meio, fator que motiva estudos geográficos desde os primórdios. Recorda-se a fala de Santos (2009) que qualifica a presença da técnica como fundamental para o alcance de uma epistemologia do espaço, permitindo a compreensão do próprio espaço e de seus períodos no decorrer do tempo.

Como consequência do alcance das técnicas na conjuntura turística, os estudos trazem os impactos causados pelo meio-técnico-científico-informacional, como um dos principais nexos que articulam os estudos analisados com a referida teoria. As pesquisas falam sobre um meio artificializado que favorece diretamente a organização de espaços turísticos, voltados para demandas globais e a serviço de finalidades díspares do local, expressando alinhamento com Santos (2009) que associa o meio-técnico-científico-informacional à globalização, reforçando parâmetros e oportunidades desiguais.

Em face dos desacordos dessas finalidades surgem questões que abordam a tecnosfera e a psicosfera, baseadas nas relações que os agentes impõem ao avanço dinâmico da atividade do turismo pelo espaço. Identificam-se questões que remetem à produção, à mercantilização de paisagens naturais e sua venda, levantando debates em torno da interferência causada pelo turismo nos parâmetros locais.

O local por sentir-se ameaçado passa a impor movimentos contrários, configurando-se como o gene revolucionário tão presente na psicosfera mencionada por Santos (2009). Assim, observa-se a tecnosfera sendo composta pela articulação dos agentes hegemônicos do turismo (Mercado e Estado) com vistas na tomada de decisão verticalizada, de objetivos próprios e indiferentes ao local, e a psicosfera por sua vez, localiza-se na desmistificação de soluções e no surgimento de contrarracionalidades que visam o empoderamento e a participação igualitária dos residentes na pauta do turismo nas localidades, ou seja, o capital social relacionado à atividade turística.

Observa-se que a transformação do meio geográfico tem rebatimentos diretos para o turismo, na medida em que a atividade turística vivencia o dilema entre a sua expansão e a sua demanda por ações sustentáveis. O conflito se estabelece na medida em que um dos principais fatores que motivam os deslocamentos turísticos, a busca por paisagens naturais, passa por transformações constantes, influenciadas pela lógica de um turismo que estimula alterações no meio natural, mesmo sabendo que ele é um dos os maiores ativos responsáveis pela motivação das viagens. 
Ao prosseguir com a análise entende-se que este cenário é facilitado pela espacialização de diversas redes, que facilitam o fluxo da informação. Os estudos analisam os lugares onde à atividade do turismo se espacializa, considerando-os participantes de uma trama de relações e atividades do turismo e de outros vetores. As redes acabam seguindo uma lógica global e hegemônica, e trazem para o debate questões de controle das decisões, fator que intervém nas diferenciações dos espaços vocacionados ao turismo.

O conceito de redes no turismo é mais que pertinente. Atesta-se que considerando somente as áreas da hotelaria, gastronomia e entretenimento, identifica-se um volume considerável de divisas que se movimentam por meio de efeito multiplicador do turismo repercutindo em redes relacionadas com diferentes setores produtivos.

Destarte, admite-se uma trama de ligações que possibilitam a troca constante de dados no turismo, facilitada por: (a) pontos de acesso (estudos, pesquisas de mercado), (b) arcos de transmissão (empresários, agentes, operadores) e (c) nós de comunicação (parcerias público-privadas, vínculos institucionais). Observa-se a rede no turismo sendo composta por um viés sociopolítico que transpassa pessoas, mensagens, valores e trocas.

Ao meditar sobre a conexão entre espaço, técnica e tempo, chama-se atenção para a maneira como os agentes hegemônicos da atividade turística operam no fomento de estruturas próprias, visando captar e atender demandas diferenciadas.

Aqui se exemplifica com o equipamento turístico Resorts ${ }^{2}$. Nota-se o empecilho, por vezes implícito, de uma fluidez que possibilite as relações sociais de trocas amplas e justas entre o visitante e o morador local (ambulantes e/ou autônomos) impedindo que o discurso propagado pelos investidores na época de desenvolvimento dos projetos se efetive na prática, como é o caso da geração de renda e do intercâmbio cultural entre outros.

Nota-se que os espaços são pensados com vistas a dificultar o acesso e aproximação não programada entre visitantes e locais, acarretando inúmeros prejuízos, uma vez que as possíveis benesses não conseguem ultrapassar os altos muros desses complexos turísticos, dotados de intencionalidades verticais. De forma associada Identifica-se o tratamento de questões sobre espaços luminosos e opacos. Uma vez que os espaços luminosos apresentam fluidez como uma de suas características, e os espaços opacos revelam rigidez para com os processos que estão sendo expostos.

É possível destacar também questões que tratam de verticalidades e horizontalidades, que para as pesquisas refletem a postura hegemônica e o discurso de mercado tão presente nas falas de seus agentes. Na contramão se identifica o incentivo de uma postura local participativa, que em alguns momentos é transformada em resistência contra os desmandos do capital.

Neste momento é possível destacar o aparecimento de questões que envolvem movimentos sociais. Identificam-se movimentos sociais nas áreas litorâneas e indígenas, ambos

2. "Apresenta os pré-requisitos básicos de um hotel cinco estrelas [...] muitas vezes menosprezam o local onde estão instalados, recriando um ambiente falso, impedindo que o turista tenha contato com a comunidade e adquira experiências originais. São indiferentes à cultura local" (MAGALHÃES, 2002, p. 71). 
vistos como produtos potenciais para a captação de novos fluxos. Também são identificados movimentos sociais que tratam de questões sobre os diversos impactos negativos gerados, por meio dos conflitos da produção dos espaços turísticos levantando questões sobre a coletividade, cidadania dentre outras.

Sobre o papel que a totalidade traz para os estudos analisados, reconhece-se que seu uso está associado diretamente ao seu reconhecimento como um elemento imprescindível para poder explicar todas as ocorrências que agem sob o espaço geográfico, motivadas pelo apelo turístico. Identifica-se na totalidade a capacidade de costurar os elementos, relações, noções e entendimentos, em um mesmo tecido espacial, permitindo assim as análises.

Por todos os processos, sejam eles naturais ou sociais, os estudos que utilizaram da teoria do espaço geográfico colocaram a totalidade como o denominador comum para validar suas explicações. Assim, questões que tratam de holismo, interação, movimento, elementos, sistemas, multiplicidade, modificações e coexistências estão presentes nas pesquisas firmando a aplicação do conceito de totalidade no espaço geográfico como Santos (2009) propôs.

Sublinhando dentre as teorias não geográficas, ainda é possível destacar que existe um grupo de teorias que delimitam seu escopo de análise em questões que entendem o turismo como produto de mercado, de venda, trazendo para o debate questionamentos sobre as fases de produção, distribuição e consumo do turismo.

Igualmente é permitido identificar um grupo de teorias voltadas para questões de crescimento econômico e desenvolvimento humano, são elas: Teorias do desenvolvimento (regional, local, desigual e sustentável) e Teoria da produção do espaço. Por fim, também se identificam teorias com propostas similares a ideia de totalidade, mesmo que algumas de suas bases se diferenciem quanto ao significado teórico ou metodológico, são elas: Teoria Geral dos Sistemas e a Teoria da Complexidade. Por tudo que foi debatido, atesta-se que as teorias agruparam distintos elementos (noções, ideias, conceitos entre outros) visando estabelecer relações lógicas entre a teoria e a empiria (Moreira, 2014), servindo de alicerce para o desenvolvimento das pesquisas avaliadas.

Enfatiza-se que a seleção da teoria é determinada pela definição do objeto de pesquisa e pelo questionamento que é feito sobre ele. E neste caso, a teoria do espaço geográfico ofertou subsídios teórico-metodológicos relevantes para a leitura do turismo pelas lentas geográficas, possibilitando a operacionalização das problemáticas dos estudos avaliados.

\section{CONCLUSÕES}

Com base na análise que trata do uso e da contribuição teórico-metodológica da teoria do espaço geográfico para os estudos (teses e dissertações) no âmbito dos programas de pós-graduação stricto sensu em Geografia no Brasil, tem-se que a teoria do espaço geográfico, de autoria de Milton Santos, apresenta relevância de uso no momento da seleção dos suportes teórico-metodológicos, que estruturam os estudos avaliados.

A referida teoria está imersa nos estudos por meio do entendimento das suas categorias de análise (formas, funções, estruturas e processos) que configuram um cenário relacional 
com a atividade do turismo, a qual agrega novas possibilidades técnicas e promove a expansão da relação entre o homem e o meio, motivando novos estudos geográficos sobre o turismo.

Como saldo desta identificação é permitido apontar o direcionamento do esforço teórico-metodológico dos estudos analisados para questões que tratam de elementos naturais e/ou físicos (recursos e paisagens naturais), assim como dos desdobramentos econômicos (geração de renda, promoção de empregos, competitividade), de planejamento (papel do Estado, políticas públicas, impactos de diversas ordens), de desenvolvimento social (movimentos sociais, agentes de desenvolvimento, perspectiva local), entre outras questões que se espacializam sob um pano de fundo da totalidade, permitindo um devido alinhamento teórico e metodológico. O turismo é entendido como participe ativo dessa dinâmica que interfere e gera distintos desdobramentos espaciais.

Refletindo sobre a teoria do espaço geográfico, enquanto base referencial para as pesquisas, é possível identificar alguns de seus principais subsídios de estruturação como vetores de orientação para as pesquisas geográficas analisadas, e para as que estão por vir.

Assim, é possível apontar o meio-técnico-científico-informacional, a totalidade, o espaço reticulado, a presença dos elementos do espaço geográfico, pares dialéticos diversos (espaços luminosos, opacos, fluidos, densos, verticalidades, horizontalidades) dentre outros elementos de composição da aludida teoria que podem ser replicados diante da práxis do turismo.

De forma complementar, Identifica-se que alguns estudos analisados mostraram-se frágeis do ponto de vista teórico, não apresentando teorias para consolidar suas análises, e quando as apresentavam, faziam um uso equivocado com sérios riscos de isolamento de questões complexas.

Desse modo, propõe-se para os cursos de geografia e turismo no Brasil, uma inserção de disciplinas que abordem temas relacionados à teoria, método, conhecimento científico, epistemologia e ontologia nos seus currículos. Atesta-se que o avanço de qualquer campo científico passa por essas abordagens.

Conclui-se que a teoria do espaço geográfico é um importante componente disciplinar que possibilita o debate interdisciplinar da ciência geográfica com o turismo, ofertando para turismólogos e geógrafos, subsídios teórico-metodológicos para estruturação das pesquisas em ambos os campos. 


\section{REFERÊNCIAS BIBLIOGRÁFICAS}

Albach, V.M.; Gândara, J. M. G. (2011). Existe uma geografia do turismo? Revista Geográfica de América Central. Número Especial EGAL. Universidad de Costa Rica. pp. 1-16

Azevedo, F. F. (2013). Turismo em foco: globalização e politicas públicas. In: Azevedo, F. F. et al. Turismo em foco (pp.11-27). Belém: NAEA.

Brasil, Ministério do turismo (2018). Anuário estatístico do turismo- ano base 2017. Dados e fatos. Recuperado em 10 de maio de 2019 de: http://www.dadosefatos.turismo.gov. br/2016-02-04-11-53-05/item/366-anu\%C3\%A1rio-estat\%C3\%ADstico-de-turismo-2018-ano-base-2017/366-anu\%C3\%A1rio-estat\%C3\%ADstico-de-turismo-2018-ano-base-2017.html

Castro, N. A. R. (2006). O lugar do turismo na ciência geográfica: contribuições teórico-metodológicas à ação educativa. (Tese de doutorado em Geografia, Universidade de São Paulo). Recuperado de www.teses.usp.br.

Castrogiovanni, A.C. (2004). Espaço turístico também é comunicação. Conexão - Comunicação e Cultura (3) 5, pp.1-2.

Cruz, R.C.A. (2001). Introdução à geografia do turismo. São Paulo: Roca.

Dantas, A. (2014). Geografia e epistemologia do sul na obra de Milton Santos. Mercator, Fortaleza. (13) 3, pp.46-61.

Gil, A.C. (2007). Métodos e técnicas de pesquisa social. 5. ed. São Paulo: Atlas.

Gómez. A. L. (1987). La evolución internacional de la Geografía del ocio. GeoCritica: Cuadernos críticos de Geografía Humana. Universidad de Barcelona, (XII). 69.

Gonçalves, H. A. (2005). Manual de monografia, dissertação e tese. 2. ed. São Paulo: Avercamp.

Iskandar, J. I. (2012). Normas da ABNT: comentadas para trabalhos científicos. 5. ed. Curitiba: Juruá.

Magalhães, C. F. (2002). Diretrizes para o turismo sustentável em municípios. São Paulo: Rocas.

Moreira, R. (2007). Pensar e ser em geografia: ensaios de história, epistemologia e ontologia do espaço geográfico. São Paulo: Contexto.

Pearce, D. G.(2003). Geografia do turismo: fluxos e regiões no mercado de viagens. São Paulo: Aleph.

Pires A. P. (2008). Amostragem e pesquisa qualitativa: ensaio teórico e metodológico. In: Poupart J, et al (org.). A pesquisa qualitativa: enfoques epistemológicos e metodológicos. Petrópolis, Rio de Janeiro: Editora Vozes. p. 154-211.

Rejowski, M. (1996). Turismo e pesquisa científica: pensamento internacional x situação brasileira. Campinas-SP: Papirus.

Richardson, R. J. et al. (2008). Pesquisa social: métodos e técnicas. 7. ed. São Paulo: Atlas.

Rodrigues, A. B. (2001). Turismo e espaço: rumo a um conhecimento transdisciplinar. 3. ed. São Paulo: Hucitec.

Santos, M. (2009). A natureza do espaço: técnica e tempo, razão e emoção. 4. ed. São Paulo: Editora da Universidade de São Paulo.(Coleção Milton Santos).

Santos, M. (2004). Por uma geografia nova: da crítica da geografia a uma geografia crítica. 6 ed. São Paulo: Editora da Universidade de São Paulo. (Coleção Milton Santos).

Santos, M; Silveira, M. L. (2001). O Brasil: território e sociedade no início do século XXI. São Paulo: Record.

Santos, M.(1994). Técnica espaço e tempo. São Paulo: Hucitec. 
Santos, M. (1988). Espaço e método. São Paulo: Nobel. (Coleção Espaços).

Silva, C. H. C (2012). O turismo e a produção do espaço: perfil geográfico de uma prática socioespacial. Geografia Ensino \& Pesquisa, 16 (2), pp.47-61.

Silva, A. C. da Silva. (1975). O litoral norte do estado de São Paulo: formação de uma região periférica. (Tese de Doutorado em Geografia, Universidade de São Paulo). Recuperado de www.teses.usp.br.

Veal, A. (2011). Metodologia de pesquisa em lazer e turismo. São Paulo: Aleph. (Série Turismo).

Vitte, A.C. (2009). Teorias do método científico e geografia: um ensaio a partir da noção de paradigma de Thomas Kuhn. In: Mendonça, F. A. et al. Espaço e tempo: complexidade e desafios do pensar e do fazer geográfico. Curitiba: Ademadan. 